\title{
PHARMACOLOGICAL TREATMENTS OF COVID-19 - A REVIEW
}

\author{
JEEJA MATHUMMEL CHERUMANALIL ${ }^{1 *}$, JAYAKRISHNAN THAYYIL ${ }^{2}$
}

${ }^{1}$ Department of Pharmacology, Government Medical College, Idukki, Kerala, India. ${ }^{2}$ Department of Community Medicine, Government Medical College, Calicut, Kerala, India. Email: jayanjeeja@yahoo.co.in

Received: 15 July 2020, Revised and Accepted: 13 August 2020

ABSTRACT

Now the world stands in the fight against coronavirus disease 2019 (COVID-19), with its early origin from Wuhan city in China. It has evolved into a global pandemic resulting into a significant burden to the human race. As per WHO, on July 31 , 2020, there were 170 million cases reported all over the world, with 6.73 lakhs deaths. There is no effective treatment so far discovered for the severe acute respiratory syndrome-CoV2. Many pharmacological agents/therapies are being used or considered for treatment. In many countries, physicians are giving COVID-19 patients treatment that has not been approved for this disease. They are treating patients using medications outside their indicated, approved uses and without study protocols, with little scientific evidence. At present, there is no evidence from randomized clinical trials (RCTs) that any potential therapy improves outcomes in patients with COVID-19. There are no clinical trial data supporting any prophylactic therapy. Along with Solidarity trial, many active clinical treatment trials are underway. This narrative review summarizes current evidence regarding major proposed treatments, repurposed or experimental, for COVID-19 and provides a summary of current clinical experience and treatment guidance for this pandemic novel coronavirus.

Keywords: Pharmacological management COVID-19, Interferon beta 1a, Tocilizumab, Remdesivir, Hydroxychloroquine, Favipiravir, LPV/r, Dexamethasone.

(C) 2020 The Authors. Published by Innovare Academic Sciences Pvt Ltd. This is an open access article under the CC BY license (http://creativecommons. org/licenses/by/4. 0/) DOI: http://dx.doi.org/10.22159/ajpcr.2020.v13i10.39055

\section{INTRODUCTION}

Now the world stands in the fight against coronavirus disease 2019 (COVID-19), with its early origin from Wuhan city in China has evolved into a global pandemic demanding a significant toll on the human race. As per WHO, on July 31, 2020, there were 170 million cases reported all over the world, with 6.73 lakhs deaths, and the USA is the worst sufferer, in terms of numbers, due to the disease [1]. Maximal precautionary measures and resources have been put forward by most nations to alleviate transmission and decrease mortality rates. Till date, there is no effective treatment so far discovered for the severe acute respiratory syndrome (SARS)-CoV2. For prevention, currently, 142 candidate vaccines are in the preclinical phase and 24 in the clinical phase, of which three entered in phase 3 stage. One indigenous vaccine has entered the phase 1 stage in India [2-6].

All over the world, many drugs and therapies are being considered or used for treatment. Doctors are using treatments that have not been approved for COVID-19. They are treating patients using drugs beyond their indicated, approved uses and with little scientific evidence or by extrapolation from in vitro studies revealing their antiviral and anti-inflammatory properties [7-9]. China, where the pandemic was originated, hospitals are using traditional Chinese medicine, which has been reported to be with good effects [10-13].

Since severe acute respiratory syndrome (SARS)-CoV-2, the causative agent of COVID-19 has a close genetic resemblance with the SARS-CoV and the Middle East respiratory syndrome (MERS)-CoV, drugs used to treat SARS and MERS was utilized to explore the extent of their activity against SARS-CoV-2. With the sudden and severe nature of the disease and its high rate of contagion, and the costs and time involved in the development and marketing of a new, safe and efficacious drug, researchers around the world are looking to repurpose known drugs to treat COVID-19 [3]. A wide range of drugs that have earlier been approved for other indications, off label use as well as several investigational drugs is being studied through clinical trials for benefit. There are currently no drugs approved for pharmacological treatment and only very few have reported to be shown some hope. Due to the urgent need for effective treatments, there has been increased interest in repurposing currently available drugs for immediate use [14]. As a large number of people all over the world are getting infected and hospitalized with SARS-CoV2 along with clinical trials generating medical information in a rapid pace, clinicians need accurate evidence regarding effective medical treatments [8]. In this context, this narrative review summarizes current evidence regarding major proposed treatments, repurposed or experimental, for COVID-19 and provides a summary of current clinical experience and treatment guidance for this.

\section{HYDROXYCHLOROQUINE (HCQ) AND CHLOROQUINE (REPURPOSED OR OFF-LABEL)}

Chloroquine and HCQ both belong to the same group 4-aminoquinolines. The former is an antimalarial agent with anti-inflammatory and immune-modulatory activities, has gained significant interest as a potential therapeutic option for the management of COVID-19. HCQ a less toxic derivative of chloroquine has demonstrated more potent inhibition of SARS-CoV-2 virus in vitro studies $[15,16]$. While the exact mechanisms of action are unknown, it is considered that these effects are mainly through alkalinization of the phagolysosome as well as inhibition of viral entry by blocking receptor binding and membrane fusion [17-21]. It has been used widely for a long time for treating conditions such as rheumatoid arthritis (RA), juvenile idiopathic arthritis, and Sjogren's syndrome [22]. Its lesser cost, fewer side effects, and safety in pregnancy make it more preferable to chloroquine $[17,18]$. On prolonged treatment, it may rarely cause cardiotoxicity manifested as cardiomyopathy or conduction abnormalities [22,23].

Although there was no evidence exists for the efficacy of HCQ treatment of coronavirus such as SARS or MERS, the earliest trials conducted in China revealed that HCQ has in vitro activity against SARS-CoV-2 [24]. One open-label, randomized controlled trial (RCT) conducted in China using HCQ in 150 patients with mild to moderate COVID-19 shows HCQ did not result in any benefit than the standard of care alone and adverse events were higher [25]. A French study among a cohort of heterogeneous patients, it has been shown to reduce SARS-CoV-2 viral loads at day 6 compared to controls [26]. However, this study has been 
criticized widely for its methodological flaws and the findings were refused [27]. In a RECOVERY trial conducted in the UK, among 1542 patients randomized to HCQ compared with 3132 patients to standard care alone, reported that there was no significant difference in the primary endpoint of 28 -day mortality of $25.7 \%$ HCQ versus $23.5 \%$ and the hazard ratio was 1.11 (95\% confidence interval 0.98-1.26; $\mathrm{p}=0.10$ ). There was also no evidence of beneficial effects on hospital stay duration or other outcomes [28]. The other two published nonrandomized comparative studies suggest an increased risk of QT prolongation among patients receiving HCQ compared to those not receiving HCQ (RR: 2.89; 95\% CI: 1.62, 5.16) [29]. A chloroquine trial in Brazil was stopped due to the risk of fatal heart complications like arrhythmia [30].

Some countries, including India HCQ, have been suggested for prophylaxis among healthcare workers who are taking care of COVID-19 patients and household contacts of patients without any evidences. Experts have warned that, if any, the potential benefit must be weighed against their increased risk of life-threatening arrhythmias. In June 2020, the first-ever internationally reported RCT conducted ( $\mathrm{n}=821)$ to study the prophylactic efficacy of HCQ for preventing COVID-19 reported that the incidence of illness did not differ significantly between participants receiving HCQ $(11.8 \%)$ and those receiving placebo (14.3\%) [31]. As per the Infectious Diseases Society of America (IDSA) report on June 22, the currently available best evidence failed to demonstrate or to exclude a beneficial effect of HCQ on clinical progression of COVID-19 as inferred by radiological findings; (risk ratio - RR: 0.61; 95\% CI: $0.26,1.43$ ) or on viral clearance by PCR tests (RR: 2.00; 95\% CI: 0.02, 20.00) [29].

Antibiotic azithromycin (AZT), used for the respiratory tract, skin infections have been used in the treatment of some viral respiratory tract infections like influenza as an adjunctive. Along with antibacterial coverage, it has got some immune-modulatory and anti-inflammatory effects $[32,33]$. Recently, it has been proven to be in vitro active against Zika and Ebola viruses [34-36].

With the above assumptions, some investigators have added AZT along with HCQ in suspected bacterial infections in COVID-19. An observational study with AZT conducted on 11 hospitalized patients remains positive for COVID-19 even after 5-6 days of the treatment [35]. In another retrospective multicentric four-arm comparative study at New York among 1438 hospitalized patients, the mortality rate was found to be more with HCQ plus AZT and also the cardiac arrest was significantly higher with the combination therapy, compared to either drug alone [37]. In a large cohort study, patients taking a 5-day course of AZT had an increased risk of sudden cardiac death with an HR of 2.71 (95\% CI 1.58-4.64) versus 0.85 (0.45-1.60), compared to patients receiving no antibiotic or amoxicillin, respectively [38]. Hence, it is better to avoid this combination therapy in a vulnerable population.

WHO in its technical guideline states that there is not, as yet, definitive pre-clinical or clinical evidence demonstrating the efficacy of HCQ as a prophylactic agent for COVID-19 [39]. On June 17, 2020, WHO announced that the HCQ arm of the Solidarity trial was being stopped because data from the trial showed that among hospitalized COVID-19 patients compared to those with on standard care, the mortality was not reduced by HCQ. WHO also mentions that this decision applies only to the conduct of the Solidarity trial and does not apply to the use or evaluation of HCQ in pre/post-exposure prophylaxis in patients exposed to COVID-19.

The dosage recommendation for HCQ has also varied widely: The prophylactic regimen recommended by Indian Council of Medical Research (ICMR) advised that 400 mg of HCQ be given twice on day 1 , then $400 \mathrm{mg}$ once weekly for 7 weeks for healthcare workers or 3 weeks for asymptomatic contacts [40]. Chinese experts recommended dosage of HCQ at $500 \mathrm{mg}$ twice daily for 10 days [41]. Earlier with the non-availability of any approved available drug US FDA has approved HCQ to treat COVID-19 on an emergency basis. The approved therapeutic dose for HCQ was $800 \mathrm{mg}$ on day 1, followed by $400 \mathrm{mg}$ daily for 4-7 days [42]. As such, the evidence base behind the use of HCQ as prophylactic or therapeutic remains limited as with other drugs and should only be used after shared decision making with the patients while awaiting the results of other on-going studies.

\section{REMDESIVIR (RDV)}

RDV is a prodrug of a nucleotide analog and RNA polymerase inhibitor and a novel broad-spectrum antiviral agent originally synthesized and developed in 2013-2014 to treat infections by hepatitis C virus and respiratory syncytial virus by Gilead Sciences [43]. During the 2014 Ebola virus outbreak, RDV demonstrated activity against Ebola virus in cell lines and in Rhesus monkeys infected with the virus $[44,45]$. However, clinical efficacy was not conclusively demonstrated in the treatment of Ebola or Marburg infections [38,46]. By in vitro and animal studies, it has documented activity against SARS-CoV and MERS $[47,48]$. Since it is a new drug, the clinical safety data were not adequately demonstrated. The documented adverse effects are gastrointestinal symptoms, elevated transaminases, and longer clotting times, and possible drug interactions with co-administration of other drugs like CYP enzymes inducers [49]. Like HCQ many clinical trials are being conducted to explore the efficacy and safety of RDV in COVID-19 [24,47,50,51]. The dosage advised for RDV for a 10-day regime was: $200 \mathrm{mg}$ loading dose on day one, followed by $100 \mathrm{mg}$ oncedaily maintenance doses for 9 days, which was similar to that of the clinical trial against the Ebola virus [52,53].

In a cohort study funded by Gilead Sciences, where RDV was administered on a compassionate basis on April 2020, clinical improvement was observed in 36/53 (67.9\%) patients [54]. This paper also reported that RDV administration for 10 days was associated with adverse events in 32/53 (60.3\%) patients, of which 23\% were serious and four patients discontinued RDV treatment prematurely [54]. Another study conducted in China, 237 patients admitted to hospital with severe diseases 158 to RDV and 79 to placebo, found that there was no difference in time to clinical improvement with the use of RDV with a hazard ratio 1.23 (95\% CI 0.87-1.75). The adverse events were reported among 66\% of RDV recipients versus $64 \%$ placebo recipients. RDV was stopped early because of adverse events in $18(12 \%)$ patients versus four (5\%) patients with placebo and was not associated with statistically significant clinical benefits [55]. Moreover, RDV was not associated with significant mortality benefit after 28 days of hospitalization, and virological clearance was observed in only $37 / 236(19 \%)$ patients. Since there were no significant clinical benefits, this trial was terminated prematurely. The explanation given by the authors for termination was that the pandemic had been brought under control in China and it was difficult for recruiting new COVID-19 cases for the study that has received many criticisms [55]. On May 1 , 2020, the US FDA granted an Emergency Use Authorization (EUA) for RDV to treat patients with "suspected or laboratory confirmed" severe COVID-19, based on a review of top-line data from two trials at US (NCT04280705, NCT04292899) [56]. The first study was sponsored by the National Institute of Allergy and Infectious Diseases and the preliminary data of the study reported that compared to placebo, RDV shortens time to recovery from 15 days to 11 days (31\%) significantly without any significant mortality benefit [57]. Another study reported patients ( $\mathrm{n}=1059.538$ vs. 521) receiving treatment with RDV had a shorter median time to recovery (median 11 vs. 15 days; HR: 1.32; 95\% CI: 1.12, 1.55; high certainty of evidence). The Kaplan-Meier estimates of mortality by 14 days were $7.1 \%$ with RDV and $11.9 \%$ with placebo (HR: 0.70; 95\% CI: 0.47-1.04) [58]. IDSA opined that additional clinical trials are needed to provide increased certainty about the potential for both benefits and harms of treatment with RDV, as well as understand the benefit of treatment based on disease severity [29]. Meanwhile, after EUA was granted for RDV use to treat COVID-19 patients in the USA, to enhance drug supply to countries, manufacture of RDV was started in India as on May 12, 2020. The Institute for Clinical and Economic Review estimated that for a 10-day course of RDV, the production cost 
will be only USD 10, but they are having a retail price of USD 4500 [59]. On June 1, 2020, Drug Controller General of India (DCGI) has granted restricted emergency use of RDV in hospitalized COVID-19 patients with moderate disease (those on oxygen) with few of contraindications like severe renal impairment, pregnancy or lactation and children below 12 years of age. Dose: $200 \mathrm{mg}$ IV on day 1 followed by $100 \mathrm{mg}$ IV daily for 5 days [59]. For final approval of RDV for treating COVID-19, also need further evidence proofs.

\section{FAVIPIRAVIR}

Favipiravir is an oral antiviral drug discovered, approved, and manufactured by Toyama chemical in Japan. It is a purine nucleic acid analog and potent RNA dependent RNA polymerase (RdRp) inhibitor [60]. In the human body, enzymes will convert to its active metabolite (ribofuranosyltriphosphate) which inhibits RdRp which are necessary for the transcription and replication of viral genomes. It is well absorbed after oral administration and its bioavailability is almost complete, but food will interfere with absorption. The drug undergoes hydroxylation primarily by aldehyde oxidase and to a lesser extent by xanthine oxidase to its inactive metabolite and T1/2 is about $2-5.5 \mathrm{~h}$, which is eliminated mainly through the renal route [61-63]. The drug has got adverse effects on hematopoietic tissues and liver, resulting in reduced RBC production, increase in liver enzymes, rise in total bilirubin, and vacuolization in hepatocytes. It has got teratogenicity effects $[61,62]$. With the limitations of the scientific evidence and doubted safety concerns, widespread use of favipiravir against COVID-19 is warranted.

The drug was initially approved for therapeutic use in resistant cases of influenza and later has been investigated for the treatment of diseases such as Ebola, Lazza, and now COVID-19. In vitro, it has proved activity against other RNA viruses and the EC50 of favipiravir against SARSCoV-2 was $61.88 \mu \mathrm{M} / \mathrm{L}$ in Vero E6 cells [24,64]. However, limited clinical experience has been reported for supporting the use of favipiravir for COVID-19. It is currently being tested in 18 clinical trials for COVID-19 and results from two studies have shown a positive outcome, while data from other trials are waiting [65]. An RCT conducted in China (ChiCTR 200030254) among 120 each COVID-19 patients have shown that favipiravir has a good recovery rate $(71.43 \%)$ compared to umifenovir (55.86\%) $\mathrm{p}=0.001$, and the duration of symptoms such as fever and cough significantly shorter, with more ADR [65]. Another RCT (https:// clinicaltrials.gov/ct2/show/NCT04359615) was going on in Tehran, Islamic Republic of Iran and a phase II trial among 50 patients are going on at the University of Massachusetts Medical School, US. In a trial among 2000 patients, it has demonstrated safety and clearance of the influenza virus by 6-14 h [65]. Glen mark, the manufacturers of favipiravir, claimed that the drug shows a clinical improvement of up to $88 \%$ in COVID-19 with a rapid reduction in viral load by 4 days. In India, a randomized multicentric study was done among 150 patients to test the drug's efficacy and safety; the study details are yet to be published [66]. Based on the data, they obtained approval for manufacture and marketing the drug for emergency restricted use for the treatment of mild to moderate patients. The DCGI without publicizing the basis of a clinical trial conducted in India has given accelerated approval to Glen mark Pharmaceuticals, an Indian pharmaceutical company on an emergency basis, to sell generic versions of favipiravir for the treatment of COVID-19 [67]. Although there is no scientific consensus on the efficacy of the drug, doctors in China and Russia started using it to treat COVID-19 patients. The drug was not yet approved by the US and UK [65]. The authors are unable to find well-designed scientific studies supporting the effectiveness and safety of this drug in COVID-19 patients. Therefore, the explanation that the grant was approved based on "evaluation of data" does not seem tenable [66]

\section{TOCILIZUMAB (TCZ) (OFF LABEL)}

TCZ is an immunosuppressive drug, mainly for the treatment of RA and systemic juvenile idiopathic arthritis, developed by Roche and Chugai Pharmaceutical [68]. It is a humanized monoclonal antibody against the interleukin-6 (IL-6) receptor by blocking their receptor. IL-6 is a cytokine that plays an important role in immune response and is implicated in the pathogenesis of many diseases such as autoimmune diseases, multiple myeloma, and prostate cancer. The drug is emerged as an alternative treatment for COVID-19 patients with a risk of cytokine storms. Safety in pregnancy and harm to the fetus was unknown [69]. They suggested that in patients with moderate disease with progressively increasing oxygen requirements and in mechanically ventilated patients not improving despite the use of steroids, TCZ may be considered. Dose prescribed is: $8 \mathrm{mg} / \mathrm{kg}(\mathrm{m}$. maximum $800 \mathrm{mg}$ at one time) given slowly in $100 \mathrm{ml}$ normal saline over $1 \mathrm{~h}$; dose can be repeated once after 12-24 h if needed [69,70]. Among COVID-19 patients, the long-term safety data of TCZ were still unknown.

In a retrospective study conducted in China on 15 subjects out of the four critically ill patients, three died, and one patient did not show a decline in $\mathrm{C}$ reactive protein levels. Ten patients achieved clinical stabilization and disease progression was seen in two cases [71]. Another study conducted by Xu et al. indicates the potential benefits of TCZ in lowering mortality in severe COVID-19 patients [69]. A prospective study among 63 patients shows administration of TCZ on $1^{\text {st }}$ day of hospital admission increases the survival chances of severe COVID-19 patients [72]. An Italian study conducted among 100 patients reported a rapid, sustained, and significant clinical improvement [73]. A retrospective cohort study conducted in Italy among 544 severe COVID-19 pneumonia, compared with the standard care group $73(20 \%)$, the death rate among the TCZ group was low 13 (7\%; p<0.0001). After adjustment for sex, age, recruiting center, duration of symptoms, and SOFA score, TCZ treatment was associated with reduced risk of invasive mechanical ventilation or death (Hazard ratio $0 \cdot 61,95 \%$ CI $0.40-0.92$ ), thus reported to reduce the risk of invasive mechanical ventilation or death in patients with severe COVID-19 pneumonia [74]. In a controlled observational study among 154 mechanically ventilated patients with severe COVID-19, TCZ was associated with a $45 \%$ reduction of death, despite a very high frequency of superinfection (54\% vs. $26 \%$ ) [75]. On the harm side, other non-COVID patients receiving TCZ were reported to be prone for other severe infections, allergic reactions [29]. Since the results of RCTs were not yet available, IDSA guideline panel recommends TCZ only in the context of a clinical trial. (Knowledge gap) [29]. Although unproved, it was recommended in India by ICMR for emergency use. After analyzing the results of RCT-COVACTA trial on July 29, 2020, TCZ, Roche's Head of global product development, publicize that TCZ fails to address COVID-19 pneumonia [76].

\section{CORTICOSTEROIDS: DEXAMETHASONE}

Corticosteroids consist of natural glucocorticoids, mineralocorticoids, and their synthetic analogs. They have an anti-inflammatory response as well as immunosuppressant actions. As a potent anti-inflammatory and anti-fibrotic drug, it may have actions to prevent an extended cytokine response and may speed up the resolution of pulmonary and systemic inflammation in COVID-19 pneumonia $[77,78]$. At the same time, there is concern that the use of corticosteroids may have negative effects by inhibition of immune response and pathogen clearance in COVID-19 [77]. At the onset of the pandemic, due to lack of evidence from clinical trials, WHO advised against the use of steroids in COVID-19 patients. However, a low dose systemic corticosteroid was indicated by Society of Critical Care Medicine and European Society of Intensive Care Medicine for treating mechanically ventilated COVID-19 patients with the acute respiratory syndrome (ARDS) [79].

Dexamethasone is a glucocorticoid 5 times more potent than methyl prednisolone with profound anti-inflammatory properties and immunosuppressant action. Furthermore, it has got less mineralocorticoid activity resulting in fluid retention which can be good for ARDS patients [80]. In COVID-19 patients, it depresses the body's immune response when it becomes too aggressive to control by other means [80]. In non-COVID ARDS patients, by decreasing ventilator days and reducing mortality, the utility of dexamethasone was well proved [81]. 
An observational study from China, among 11 of 31 severe patients with COVID-19 who received corticosteroid treatment, reported no association between steroid treatment and virus clearance time, length of hospital stay, or duration of symptoms [82]. A retrospective cohort study in COVID-19 patients with pneumonia, with ARDS, treatment with methyl prednisolone was reported to be associated with a $62 \%$ relative risk reduction of mortality [83]. These data indicate the chance of utilizing steroids proportional to the severity. Villar et al. consider that in patients of COVID-19 with ARDS, corticosteroid can be lifesaving in severe life-threatening cytokine storm [84].

On June 16, 2020, the recovery trial from the University of Oxford announced preliminary results stating that the cheap and widely available corticosteroid dexamethasone can shorten mortality in patients with severe forms of COVID-19 by a third and improves survival rates of hospitalized patients receiving oxygen or on ventilator [85]. They compared mortality in 2104 patients randomized to dexamethasone $6 \mathrm{mg}$ once a day for 10 days and 4321 patients randomized to standard care alone. They found that dexamethasone reduced deaths by one-third in ventilated patients and the rate ratio (RR) was 0.65 (95\% confidence interval $0.48-0.88$ $\mathrm{p}=0.0003$ ) and by one-fifth in other patients receiving oxygen only (RR $0.80,0.67-0.96 ; p=0.0021)$. Those patients who did not require respiratory support, there was no benefit (RR 1.22, 0.86-1.75; $\mathrm{p}=0.14$ ) [85]. In a systematic review based on available studies, it was found that among hospitalized patients, 28-day mortality was $17 \%$ lower in the dexamethasone group than in the non-dexamethasone group (RR 0.83; 0.74-0.92) and have a benefit of early discharge from the hospital (RR: 1.11; 95\% CI: 1.04, 1.19) suggests glucocorticoids for patients with severe COVID-19 [86]. IDSA report use of corticosteroids is on conditional recommendation and very low certainty of evidence was now changed according to this review $[29,86]$. At the same time, there is no evidence that dexamethasone works for patients with mild disease or as a preventive measure [85,87]. The trial data suggest that dexamethasone cut the risk of death in patients with ventilator or oxygen support, so it should be reserved for seriously ill and critical patients receiving COVID-19 treatment in a hospital setting $[87,88]$. WHO is on the process of updating treatment guidelines to include dexamethasone or other steroids for COVID-19 patients.

\section{LOPINAVIR/RITONAVIR (LPV/R)}

Protease enzyme inhibitors are a class of antiviral drugs which prevent viral replication by selectively binding to viral protease enzyme and blocking proteolytic cleavage of protein precursors that are necessary for the production of infectious viral particles. Lopinavir is exclusively available only in combination with ritonavir (RTV) which improves its bioavailability. $\mathrm{LPV} / \mathrm{r}$ is a fixed-dose combination medication widely used for the treatment of HIV/AIDs first marketed by Abbott [89]. In an in vitro study, lopinavir showed an antiviral effect against SARS-CoV-2 in vitro E6 cells. Early reports of LPV/r for the treatment of COVID-19 are mostly case reports and small retrospective, non-randomized cohort studies, making it difficult to ascertain the direct treatment effect. Most of them reported no benefit beyond standard care. Diarrhea, nausea, and asthenia were the most frequently reported adverse effects in patients receiving $\mathrm{LPV} / \mathrm{r}$ regimen [89].

A study conducted among 47 COVID-19 patients compared the treatment of pneumonia-associated standard drugs alone with the combination treatment with $\mathrm{LPV} / \mathrm{r}$ and standard drugs, has a more evident therapeutic effect [90]. This retrospective cohort study from Korea included patients with COVID-19 treated with LPV/r (n=31) or HCQ $(n=34)$. Treatment with $L P V / r$ was associated with more rapid viral clearance than HCQ in mild to moderate COVID-19 (adjusted hazard ratio, 2.28; 95\% confidence interval, 1.24-4.21) [91]. For evidences these findings should be confirmed in RCT [91]. In an RCT from China (ChiCTR2000029308), 199 patients SARS-CoV-2 99 were assigned to the LPV/r group, and 100 to the standard-care group. There was no reported benefit in the time for clinical improvement (hazard ratio 1.31; $95 \%$ confidence interval $[\mathrm{CI}], 0.95-1.80$ ) and there is no significant difference in mortality at 28 days (19.2\% vs. $25.0 \%$; $95 \%$ $\mathrm{CI},-17.3-5.7)$. The treatment was stopped early in 13 patients $(13.8 \%)$ because of serious adverse events [89]. A dynamic, systematic review conducted for risk-benefit assessment of $\mathrm{LPV} / \mathrm{r}$ in comparison to the standard of care concluded that time to clinical improvement was not significantly different (hazard ratio 1.31, 95\% CI 0.95-1.80) [92]. As published on June $29^{\text {th }}$ in RECOVERY trial total of 1596 patients were randomized to $\mathrm{LPV} / \mathrm{r}$ and compared with 3376 patients randomized to usual care alone. The primary endpoint of 28-day mortality was without any significant difference in both groups $(22.1 \% \mathrm{LPV} / \mathrm{r}$ vs. $21.3 \%$ usual care; relative risk 1.04; 95\% confidence interval 0.91-1.18; $\mathrm{p}=0.58$ ) and the results were consistent in different subgroups of patients [93]. There was also no evidence of beneficial effects on the risk of progression to mechanical ventilation or length of hospital stay [93]. IDSA reported that based on a modified intention to treat analysis, treatment with $\mathrm{LPV} / \mathrm{r}$ failed to show or exclude a beneficial effect on mortality (RR: 0.67; $95 \%$ CI: $0.38,1.17$ ), and $14 \%$ of $\mathrm{LPV} / \mathrm{r}$ recipients were unable to complete the full 14-day course of administration due to adverse events [29]. The oxford COVID-19 evidence service team declared that currently there is no strong evidence for the efficacy of these drugs and the limited studies identified were subject to methodological flaws [94], and on July 4, WHO announced the stoppage use of LPV/r in solidarity arm [95].

\section{INTERFERON (IFN) BETA-1A (ALSO KNOWN AS IFN BETA 1-ALPHA)}

IFNs are low molecular weight glycoprotein cytokines produced by host cells in response to viral infections. They have nonspecific antiviral as well as other complex effects on immunity and cell proliferation. IFNs inhibit many RNA and DNA viruses, but they are host specific: Those produced by another species have poor activity in man. Three types of human IFNs are (IFN- $\alpha$, IFN- $\beta$, and IFN gamma) known to have antiviral activity. IFN- $\beta$ is primarily synthesized from human fibroblasts. IFN- $\alpha$ and IFN- $\beta$ exert potent antiviral effects while IFN gamma has antiviral as well as immune-modulatory effects. IFN- $\alpha$ can be used to treat hepatitis B and $C$ infections, while IFN- $\beta$ can be used to treat multiple sclerosis [96]. A preprint paper reported a prospective observational study conducted in Cuba among 814 confirmed SARS-CoV-2 patients among 761 (93.4\%) were treated with IFN alpha $2 \mathrm{~b}$ and 53 received the standard treatment. The proportion of fully recovered patients was respectively as $95.4 \%$ versus $26.1 \%$, $\mathrm{p}<0.01$ ). The CFR was 0.92 versus $2.95 \%$ [97]. Another exploratory study reported IFN treatment on accelerated viral clearance and reductions in circulating IL- 6 and CRP levels among 77 patients after adjusting for age, sex, and co-morbidities [98]. For the use of IFNs in COVID-19, further evidences are needed.

\section{SOLIDARITY TRIAL}

For finding an effective treatment for COVID-19, an international clinical trial named "Solidarity" was launched by the World Health Organization and its partners with member countries as participants. In this trial, the effectiveness of "new suggested options" were compared with standard care available in those countries [99]. The treatment options were originally selected based from laboratory, animal, and clinical studies. By enrolling patients in multiple countries and conducting trials will help the medical community to discover whether any of the drugs show benefits. The data will be disseminated by WHO on a real-time basis. Many of the available information is quoted, discussed in the above paragraphs. Newer options of drugs can be added based on emerging evidence. WHO cautioned that until there are sufficient proved evidences about safety and effectiveness, the suggested drugs should be used with caution and should not be widely promoted. Based on the results of trial's on HCQ and LPV/RTV and on the recommendation from the Solidarity Trial's International Steering Committee, WHO discontinue the above two treatment options from the trial on July 4,2020 . In this trial, the remaining drugs are RDV and IFN beta Ia [99]. A systematic review based on the protocols and clinical trial registries of various countries opined that the Solidarity trial was difficult to implement; it was impractical and disconnected from the 
pandemic reality, so it may not be able to give conclusions before the end of the pandemic [100].

\section{CONCLUSION}

Thus far, in the COVID-19 pandemic, most often therapeutic management has been initiated and altered either on the basis of individual case reports and physician opinion, rather than of randomized trials. As per the above review information available till date, no new NCE/drugs were invented for COVID-19. Most of the drugs suggested were off label use. At present, there is no evidence from RCTs that any suggested therapy supporting prophylactic or curative for COVID-19. The only drug proved to be useful by large RCT was dexamethasone. Other antivirals were ruled out for its efficacy in treating COVID-19. In these uncertain situations, ideally, physicians should judiciously use drugs based on scientific evidences. So until enough evidence is gathered that one treatment is superior to another, we should be sceptical of any purported therapeutic regime and should be updated.

\section{AUTHORS' CONTRIBUTIONS}

Both authors have contributed equally in all processes of preparing this paper (conceiving ideas, acquiring data, preparation of manuscript, reviewing, and editing manuscript).

\section{CONFLICTS OF INTEREST}

The authors have no conflicts of interest.

\section{AUTHORS' FUNDING}

The authors have received no funding for conducting this study or preparation and submission of this manuscript.

\section{REFERENCES}

1. World Health organization. Coronavirus Disease (COVID-2019) Situation Reports. Geneva: World Health Organization; 2020. Available from: https://www.who.int/emergencies/diseases/novelcoronavirus-2019/situationreports?

2. World Health Organization. Draft Landscape of COVID-19 Candidate Vaccines. Geneva: World Health Organisation; 2020.

3. Folegatti PM, Ewer KJ, Aley PK, Angus B, Becker S, Belij-Rammerstorfer S, et al. Safety and immunogenicity of the ChAdOx1 nCoV-19 vaccine against SARS-CoV-2: A preliminary report of a phase 1/2, single-blind, randomised controlled trial. Lancet 2020;396:467-8

4. Jackson LA, Anderson EJ, Rouphael NG, Roberts PC, Makhene M, Coler RN, et al. An mRNA vaccine against SARS-CoV-2-preliminary report. N Engl J Med 2020;1:NEJMoa2022483.

5. COVAXINTM-India's First Indigenous COVID-19 Vaccine. Available from: https://www.bharatbiotech.com/covaxin.html

6. Zhu FC, Guan XH, Li YH, Huang JY, Jiang T, Hou LH, et al. Immunogenicity and safety of a recombinant adenovirus type-5vectored COVID-19 vaccine in healthy adults aged 18 years or older: A randomised, double-blind, placebo-controlled, phase 2 trial. Lancet 2020;396:479-88.

7. Kalil AC. Treating COVID-19-Off-label drug use, compassionate use, and randomized clinical trials during pandemics. JAMA 2020;323:1897-8.

8. Zagury-Orly I, Schwartzstein RM. Covid-19-A reminder to reason. N Engl J Med 2020;383:e12.

9. Sasmi MB, Jose M, Kuttichira P. Current therapeutic options for coronavirus disease-2019-A pharmacological review. Asian J Pharm Clin Res 2020;13:42-50.

10. Ji S, Bai Q, Wu X, Zhang DW, Wang S, Shen JL, et al. Unique synergistic antiviral effects of shufeng jiedu capsule and oseltamivir in influenza A viral-induced acute exacerbation of chronic obstructive pulmonary disease. Biomed Pharmacother 2020;121:109652.

11. Cheng DZ. Clinical effectiveness and case analysis in 54 NCP patients treated with lianhuaqingwen granules [in Chinese]. World Chin Med 2020;15:150-4.

12. Yao KT, Liu MY, Li X, Huang JH, Cai HB. Retrospective clinical analysis on treatment of novel coronavirus-infected pneumonia with traditional Chinese medicine Lianhua-Qingwen. Chin J Exp Tradit Med Form 2020;:1-7.

13. Sanders JM, Monogue MM, Jodlowski TZ, Cutrell JB. Pharmacologic treatments for coronavirus disease 2019 (COVID-19): A review. JAMA $2020 ;: 6019$.

14. Wu R, Wang L, Kuo HD, Shannar A, Peter R, Chou PJ, et al. An update on current therapeutic drugs treating COVID-19. Curr Pharmacol Rep 2020:1-15.

15. Yao X, Ye F, Zhang M, Cui C, Huang B, Niu P, et al. In vitro antiviral activity and projection of optimized dosing design of hydroxychloroquine for the treatment of severe acute respiratory syndrome coronavirus 2 (SARS-CoV-2). Clin Infect Dis 2020;71:732-9.

16. Savarino A, Di Trani L, Donatelli I, Cauda R, Cassone A. New insights into the antiviral effects of chloroquine. Lancet Infect Dis 2006;6:67-9.

17. Gao J, Tian Z, Yang X. Breakthrough: Chloroquine phosphate has shown apparent efficacy in treatment of COVID-19 associated pneumonia in clinical studies. Biosci Trends 2020;14:72-3.

18. Zhou D, Dai SM, Tong Q. COVID-19: A recommendation to examine the effect of hydroxychloroquine in preventing infection and progression. J Antimicrob Chemother 2020;75:1667-70.

19. Rynes RI. Antimalarial drugs in the treatment of rheumatological diseases. Br J Rheumatol 1997;36:799-805.

20. Schultz KR, Gilman AL. The lysosomotropic amines, chloroquine and hydroxychloroquine: A potentially novel therapy for graft-versus-host disease. Leuk Lymphoma 1997;24:201-10.

21. Mauthe M, Orhon I, Rocchi C, Zhou X, Luhr M, Hijlkema KJ, et al. Chloroquine inhibits autophagic flux by decreasing autophagosomelysosome fusion. Autophagy 2018;14:1435-55.

22. Jorge A, Ung C, Young LH, Melles RB, Choi HK. Hydroxychloroquine retinopathy-Implications of research advances for rheumatology care. Nat Rev Rheumatol 2018;14:693-703.

23. Joyce E, Fabre A, Mahon N. Hydroxychloroquine cardiotoxicity presenting as a rapidly evolving biventricular cardiomyopathy: Key diagnostic features and literature review. Eur Heart J Acute Cardiovasc Care 2013;2:77-83.

24. Wang M, Cao R, Zhang L, Yang X, Liu J, Xu M, et al. Remdesivir and chloroquine effectively inhibit the recently emerged novel coronavirus (2019-nCoV) in vitro. Cell Res 2020;30:269-71.

25. Tang W, CaoZ, Han M, Wang Z, Chen J, Sun W, etal. Hydroxychloroquine in patients with mainly mild to moderate coronavirus disease 2019: Open label, randomized controlled trial. BMJ 2020;369:m1849.

26. Pastick KA, Okafor EC, Wang F, Lofgren SM, Skipper CP, Nicol MR, et al. Review: Hydroxychloroquine and chloroquine for treatment of SARS-CoV-2 (COVID-19). Open Forum Infect Dis 2020;7:ofaa130.

27. Jun C, Danping L, Li L, Ping L, Qingnian X, Lu X, et al. A pilot study of hydroxychloroquine in treatment of patients with common coronavirus disease-19 (COVID-19). Zhejiang Da Xue Xue Bao Yi Xue Ban 2020;49:215-9.

28. Thomas K, Sheikh K. Small Chloroquine Study Halted Over Risk of Fatal Heart Complications. New York: The New York Times; 2020. Available from: https://www.nytimes.com/2020/04/12/health/ chloroquine-coronavirus-trump.html.

29. Bhimraj A, Morgan RL, Shumaker AH, Lavergne V, Baden L, Cheng VC, et al. Infectious diseases society of America guidelines on the treatment and management of patients with COVID-19. Clin Infect Dis 2020;:ciaa478.

30. Available from: https://www.recoverytrial.net/news/statement-fromthe-chief-investigators-of-therandomised-evaluation-of-covid-19therapy-recovery-trial-on-hydroxychloroquine-5-june-2020-no-clinical-benefit-from-use-of-hydroxychloroquine-in-hospitalised-patientswith-covid-19.

31. Boulware DR, Pullen MF, Bangdiwala AS, Pastick KA, Lofgren SM, Okafor EC, et al. A randomized trial of hydroxychloroquine as postexposure prophylaxis for Covid-19. N Engl J Med 2020;383:517-25.

32. Gautret P, Lagier JC, Parola P, Hoang VT, Meddeb L, Mailhe M, et al. Hydroxychloroquine and azithromycin as a treatment of COVID-19: Results of an open-label non-randomized clinical trial. Int J Antimicrob Agents 2020;56:105949.

33. Ishaqui AA, Khan AH, Sulaiman SA, Alsultan MT, Khan I, Naqvi AA. Assessment of efficacy of oseltamivir-azithromycin combination therapy in prevention of influenza-A (H1N1)pdm09 infection complications and rapidity of symptoms relief. Expert Rev Respir Med 2020;14:533-41.

34. Retallack H, Di Lullo E, Arias C, Knopp KA, Laurie MT, Sandoval-Espinosa $\mathrm{C}$, et al. Zika virus cell tropism in the developing human brain and inhibition by azithromycin. Proc Natl Acad Sci USA. 2016;113:14408-13

35. Bacharier LB, Guilbert TW, Mauger DT, Boehmer S, Beigelman A, Fitzpatrick AM, et al. Early administration of azithromycin and prevention of severe lower respiratory tract illnesses in preschool 
children with a history of such illnesses: A randomized clinical trial. JAMA 2015;314:2034-44.

36. Madrid PB, Panchal RG, Warren TK, Shurtleff AC, Endsley AN, Green CE, et al. Evaluation of Ebola virus inhibitors for drug repurposing. ACS Infect Dis 2015;1:317-26.

37. Rosenberg ES, Dufort EM, Udo T, Wilberschied LA, Kumar J, Tesoriero $\mathrm{J}$, et al. Association of treatment with HCQ or AZT with in-hospital mortality in patients with COVID-19 in New York State. JAMA 2020;24:2493-502

38. Ray WA, Murray KT, Hall K, Arbogast PG, Stein CM. Azithromycin and the risk of cardiovascular death. N Engl J Med 2012;366:1881-90.

39. World Health Organization. Coronavirus disease (COVID-19) Technical Guidance: Patient Management. Geneva: World Health Organization; 2019. Available from: https://www.who.int/emergencies/diseases/ novelcoronavirus-2019/technical-guidance/patient-management. [Last accessed on 2020 Apr 15].

40. Indian Council of Medical Research. Advisory on the Use of HydroxyChloroquineas Prophylaxis forSARS- CoV-2 Infection. New Delhi: Indian Council of Medical Research; 2020.Available from: https: // www. mohfw. gov.inpdf/ Advisory on the use of hydroxychloroquine as prophylaxis for SARS COVID19 infection.pdf. [Last accessed on 2020 May 06].

41. Multicenter Collaboration Group of Department of Science and Technology of Guangdong Province and Health Commission of Guangdong Province for Chloroquine in the Treatment of novel coronavirus Pneumonia. Expert consensus on chloroquine phosphate for the treatment of novel coronavirus pneumonia. Zhonghua Jie $\mathrm{He} \mathrm{He}$ $\mathrm{Hu}$ Xi Za Zhi 2020;43:185-8.

42. Food and Drug Administration. Fact Sheet for Health Care Providers. Emergency Use Authorization (EUA) of Hydroxyl Chloroquine Sulfate Supplied from the Strategic National Stockpile for Treatment of COVID-19 in Certain Hospitalized Patients. United States: Food and Drug Administration; 2020. Available from: https://www.fda.gov/ media/136537/download. [Last accessed on 2020 May 06].

43. Siegel D, Hui HC, Doerffler E, Clarke MO, Chun K, Zhang L, et al. Discovery and synthesis of a phosphoramidate prodrug of a pyrrolo[2,1-f] [triazin-4-amino] adenine C-nucleoside (GS-5734)for the treatment of Ebola and emerging viruses. J Med Chem 2017;60:1648-61.

44. Warren TK, Jordan R, Lo MK, Ray AS, Mackman RL, Soloveva V, et al. Therapeutic efficacy of the small molecule GS-5734 against Ebola virus in rhesus monkeys. Nature 2016;531:381-5.

45. Jacobs M, Rodger A, Bell DJ, Bhagani S, Cropley I, Filipe A, et al. Late Ebola virus relapse causing meningoencephalitis: A case report. Lancet 2016;388:498-503.

46. Sheahan TP, Sims AC, Leist SR, Schafer A, Won J, Brown AJ, et al. Comparative therapeutic efficacy of remdesivir and combination lopinavir, ritonavir, and interferon beta against MERS-CoV. Nat Commun 2020;11:222.

47. Scavone C, Brusco S, Bertini M, Sportiello L, Rafaniello C, Zoccoli A, et al. Current pharmacological treatments for COVID-19: What's next? Br J Pharmacol 2020;:15072.

48. de Wit E, Feldmann F, Cronin J, Jordan R, Okumura A, Thomas T, et al. Prophylactic and therapeutic remdesivir (GS-5734) treatment in the rhesus macaque model of MERS-CoV infection. Proc Natl Acad Sci USA 2020;117:6771-6.

49. National Institutes of Health. Potential Antiviral Drugs under Evaluation for the Treatment of COVID-19; 2020. Available from: https://www. covid19treatmentguidelines.nih.gov/antiviral-therapy. [Last accessed on 2020 May 14].

50. Gordon CJ, Tchesnokov EP, Feng JY, Porter DP, Gotte M. The antiviral compound remdesivir potently inhibits RNA-dependent RNA polymerase from Middle East respiratory syndrome coronavirus. J Biol Chem 2020;295:4773-9.

51. Amirian ES, Levy JK. Current knowledge about the antivirals remdesivir (GS-5734) and GS-441524 as therapeutic options for coronaviruses. One Health 2020;9:100128.

52. National Library of Medicine-National Institutes of Health. Mild/ Moderate 2019-nCoV Remdesivir RCT. United States: NIH; 2020. Available from: https://www.clinicaltrials.gov/ct2/show/ NCT04252664.

53. National Library of Medicine-National Institutes of Health. Severe 2019-nCoV Remdesivir RCT. United States: NIH; 2020. Available from: https://www.clinicaltrials.gov/ct2/show/NCT04257656.

54. Grein J, Ohmagari N, Shin D, Diaz G, Asperges E, Castagna A, et al. Compassionate use of remdesivir for patients with severe Covid-19. N Engl J Med 2020;382:2327-36.

55. Wang Y, Zhang D, Du G, Du R, Zhou J, Jin Y, et al. Remdesivir in adults with severe COVID-19: A randomised, double-blind, placebocontrolled, multicentre trial. Lancet 2020;395:1569-78.

56. US Food and Drug Administration. Letter of Emergency Use Authorization (EUA) for Emergency Use of Remdesivir for the Treatment of Hospitalized 2019 Coronavirus Disease (COVID-19) Patients, to Gilead Sciences, Inc.; 2020. Available from: https://www. fda.gov/media/137564/download. [Last accessed on 2020 May 06].

57. National Institutes of Health. Covid-19 Treatment Guidelines: Remdesivir; 2020. Available from: https://www. covid19treatmentguidelines.nih.gov/antiviral-therapy/remdesivir.

58. Beigel JH, Tomashek KM, Dodd LE. Remdesivir for the treatment of Covid-19-Preliminary report. N Engl J Med 2020;1:NEJMoa2007764.

59. Clinical Management Protocol Covid 19. Government of India Ministry of Health and Family welfare. Version 5; 2020. Available from: https://www.mohfw.gov.in/pdf/ UpdatedClinicalManagementProtocolforCOVID19dated03072020.pdf.

60. Du YX, Chen XP. Favipiravir: Pharmacokinetics and concerns about clinical trials for 2019-nCoV infections. Clin Pharmacol Ther 2020;108:242-7.

61. Furuta Y, Gowen BB, Takahashi K, Shiraki K, Smee DF, Barnard DL. Favipiravir (T-705), a novel viral RNA polymerase inhibitor. Antiviral Res 2013;100:446-54.

62. De Clercq E. New nucleoside analogues for the treatment of hemorrhagic fever virus infections. Chem Asian J 2019;14:3962-8.

63. Shiraki K, Daikoku T. Favipiravir, an anti-influenza drug against lifethreatening RNA virus infections. Pharmacol Ther 2020;209:107512.

64. Furuta Y, Komeno T, Nakamura T. Favipiravir (T-705), a broad spectrum inhibitor of viral RNA polymerase. Proc Jpn Acad Ser B Phys Biol Sci 2017;93:449-63

65. Chen C, Zhang Y, Huang J, Yin P, Cheng Z, Wu J, et al. Favipiravir Versus Arbidol for COVID-19: A Randomized Clinical Trial. medRxiv; 2020.

66. Kalantri SP, Thakur D. The DCGI has Granted Approval for Use of the Drug to Treat Mild COVID-19 Patients, But on What Basis? Available from: https://www.thehindu.com/opinion/op-ed/the-many-questionsabout-favipiravir/article31908725.ece.

67. Glenmark Gets Regulatory Approval for Favipiravir to Treat Covid-19. Available from: https://www.pharmaceutical-technology.com/news/ glenmark-favipiravir-covid-nod.

68. Fu B, Xu X, Wei H. Why tocilizumab could be an effective treatment for severe COVID-19? J Transl Med 2020;18:164.

69. Xu X, Han M, Li T, Sun W, Wang D, Fu B, et al. Effective treatment of severe COVID-19 patients with tocilizumab. Proc Natl Acad Sci USA 2020;117:10970-5.

70. Genentech. Actemra (Tocilizumab). South San Francisco, CA: Genentech, Inc.; 2019. Available from: https://www.accessdata.fda. gov/drugsatfda docs/label/2019/125276s127,125472s040lbl.pdf. [Last accessed on 2020 Mar 17].

71. Luo P, LiuY, Qiu L, Liu X, Liu D, Li J, et al. Tocilizumab treatment in COVID-19: A single center experience. J Med Virol 2020;92:814-8.

72. Sciascia S, Aprà $\mathrm{F}$, Baffa $\mathrm{A}$, Baldovino $\mathrm{S}$, Boaro $\mathrm{D}$, Boero $\mathrm{R}$, et al. Pilot prospective open, single-arm multicentre study on off-label use of tocilizumab in patients with severe COVID-19. Clin Exp Rheumatol 2020;38:529-32.

73. Toniati O, Piva S, Cattalini M, Garrafa E, Regola F, Castelli F, et al. Tocilizumab for the treatment of severe COVID-19 pneumonia with hyperinflammatory syndrome and acute respiratory failure: A single center study of 100 patients in Brescia, Italy. Autoimmune Rev 2020;19:102568

74. Guaraldi G, Meschiari M, Cozzi-Lepri A, Milic J, Tonelli R, Menozzi M, et al. Tocilizumab in patients with severe COVID-19: A retrospective cohort study. Lancet Rheumatol 2020;2:E474-84

75. Somers EC, Eschenauer GA, Troost JP, Golob JL, Gandhi TN, et al. Tocilizumab for treatment of mechanically ventilated patients with COVID-19. Clin Infect Dis 2020;: ciaa954.

76. The Hindu Tocilizumab Fails to Address COVID-19 Pneumonia. Chennai, Tamil Nadu: The Hindu; 2020. Available from: https://www. thehindu.com/sci-tech/health/tocilizumab-fails-to-address-covid-19pneumonia/article32224050.ece.

77. Russell CD, Millar JE, Baillie JK. Clinical evidence does not support corticosteroid treatment for 2019-nCoV lung injury. Lancet 2020;395:10223:473-5.

78. Villar J, Belda J, Anon JM, Blanco J, Perez-Mendez L, Ferrando C, et al. Evaluating the efficacy of dexamethasone in the treatment of patients with persistent acute respiratory distress syndrome: Study protocol for a randomized controlled trial. Trials 2016;17:342.

79. Alhazzani W, Meller MH, Arabi YM, Loeb M, Gong MN, Fan E, et al. 
Surviving sepsis campaign: Guidelines on the management of critically ill adults with coronavirus disease 2019(COVID-19). Crit Care Med 2020;48:6:440.

80. National Institute of Health Research. Published 2020 June 16. Available from: https://www.nihr.ac.uk/news/first-drug-to-reducemortality-in-hospitalised-patients-with-respiratory-complications-ofcovid-19-found/25061.

81. Villar J, Ferrando C, Martinez D, Ambros A, Munoz T, Soler JA, et al. Dexamethasone treatment for the acute respiratory distress syndrome: A multicentre, randomised controlled trial. Lancet Respir Med 2020;8:3:267-76

82. Zha L, Li S, Pan L, Tefsen B, Li Y, French N, et al. Corticosteroid treatment of patients with coronavirus disease 2019(COVID-19). Med J Aust 2020;212:9:416-20.

83. Wu C, Chen X, Cai Y, Xia J, Zhou X, Xu S, et al. Risk factors associated with acute respiratory distress syndrome and death in patients with coronavirus disease 2019 pneumonia in Wuhan, China, JAMA Intern Med 2020;1:e200994.

84. Villar J, Confalonieeri M, Pastores M, Meduri GU. Rationale for prolonged corticosteroid treatment in the acute respiratory distress syndrome caused by coronavirus disease 2019. Crit Care Explor 2020;2:4:e0111

85. RECOVERY. Randomized Evaluation of Covid 19 Therapy. Low-cost Dexamethasone Reduces Death by up to One Third in Hospitalised Patients with Severe Respiratory Complications of COVID-19. Available from: https://www.recoverytrial.net/news.

86. Infectious Diseases Society of America Guidelines on the Treatment and Management of Patients with COVID-19. Available from: https:// www.idsociety.org/practice-guideline/covid-19-guideline-treatmentand-management. [Last accessed on 2020 Jun 25].

87. Important to Use Dexamethasone Only for Serious COVID Cases WHO. Available from: https://www.reuters.com/article/us-healthcoronavirus-who-dexamethasone/important-to-use-dexamethasoneonly-for-serious-covid-cases-who-idUSKBN23O2MT. [Last accessed on 2020 Jul 08]

88. World Health Organization. Director General's Opening Remarks at the Media Briefing on COVID-19. Available from: https://www.who. $\mathrm{int} / \mathrm{dg} / \mathrm{speeches/detail/who-director-general-s-opening-remarks-at-the-}$ media-briefing-on-covid-19. [Last accessed on 2020 Jun 22].

89. Cao B, Wang Y, Wen D, Liu W, Wang J, Fan G, et al. A trial of lopinavir- ritonavir in adults hospitalized with severe Covid-19. N Engl J Med 2020;382:1787-99.

90. Ye XT, Luo Y, Xia S, Sun Q, Ding J, Zhou Y. Clinical efficacy of lopinavir/ritonavir in the treatment of Coronavirus disease 2019. Eur Rev Med Pharmacol Sci 2020;24:3390-6.

91. Kim JW, Kim EJ, Kwon HH, Jung CY, Kim KC, Choe JY. Lopinavirritonavir versus hydroxychloroquine for viral clearance and clinical improvement in patients with mild to moderate coronavirus disease 2019. Korean J Intern Med 2020;1:224.

92. Osborne V, Davies M, Lane S, Evans A, Denyer J, Dhanda S, et al. Lopinavir-ritonavir in the treatment of COVID-19: A dynamic systematic benefit-risk assessment. Drug Saf 2020;43:809-21.

93. RECOVERY Randomized Evaluation of Covid 19 Therapy. Available from: https://www.recoverytrial.net/news/no-clinical-benefit-fromuse-of-lopinavir-ritonavir-in-hospitalised-covid-19-patients-studiedin-recovery. [Last accessed on $2020 \mathrm{Jul}$ 08]

94. On behalf of the Oxford Covid-19 Evidence Service Team. Centre for Evidence Based Medicine, Nuffield Department of Primary Care Health Sciences. Available from: https://www.cebm.net/covid-19/ lopinavir-ritonavir-a-rapid-review-of-the-evidence-for-effectivenessin-treating-covid. [Last accessed on 2020 Jul 14].

95. World Health Organization. Geneva. Available from: https:// www.who.int/news-room/detail/04-07-2020-who-discontinueshydroxychloroquine-and-lopinavir-ritonavir-treatment-arms-forcovid-19.

96. Markowitz CE. Interferon beta: Mechanism of action and dosing issues. Neurology 2007;68:s8-11.

97. Pereda R, Gonzalez D, Rivero H, Rivero J, Perez A, del Rosario Lopez L, et al. Therapeutic effectiveness of interferon-alpha2b against COVID-19: The Cuban experience. Available from: https://www. medrxiv.org/content/10.1101/2020.05.29.20109199v1.

98. Zhou Q, Chen V, Shannon CP, Shan X, Xiang X, Wang X. Interferon$\alpha 2 b$ treatment for COVID-19. Front Immunol 2020;11:1061.

99. World Health Organization. Geneva. Available from: https://www.who. int/emergencies/diseases/novel-coronavirus-2019/global-research-onnovel-coronavirus-2019-ncov/solidarity-clinical-trial-for-covid-19treatments.

100.Toumi M, Liang S, Dabbous M, Wang Y, Qiu T, Han R. COVID-19: Why SOLIDARITY and DisCoVeRy Trials may Fail to Bring Informative and Timely Results. medRxiv; 2020. 